\title{
Treatment of Klebsiella Pneumoniae Carbapenemase (KPC) infections: a review of published case series and case reports
}

\author{
Grace C Lee ${ }^{1,2^{*}}$ and David S Burgess ${ }^{3}$
}

\begin{abstract}
The emergence of Klebsiella pneumoniae carbapenemases (KPCs) producing bacteria has become a significant global public health challenge while the optimal treatment remains undefined. We performed a systematic review of published studies and reports of treatment outcomes of KPC infections using MEDLINE (2001-2011). Articles or cases were excluded if one of the following was fulfilled: no individual patient data provided, no treatment regimen specified, no treatment outcome specified, report of colonization, or greater than three antibiotics were used to treat the KPC infection. Data extracted included patient demographics, site of infection, organism, KPC subtype, antimicrobial therapy directed at KPC-infection, and treatment outcome. Statistical analysis was performed in an exploratory manner. A total of 38 articles comprising 105 cases were included in the analysis. The majority of infections were due to K. pneumoniae (89\%). The most common site of infection was blood (52\%), followed by respiratory (30\%), and urine (10\%). Forty-nine (47\%) cases received monotherapy and 56 (53\%) cases received combination therapy directed at the KPC-infection. Significantly more treatment failures were seen in cases that received monotherapy compared to cases who received combination therapy ( $49 \%$ vs $25 \% ; p=0.01$ ). Respiratory infections were associated with higher rates of treatment failure with monotherapy compared to combination therapy (67\% vs $29 \% \mathrm{p}=0.03$ ). Polymyxin monotherapy was associated with higher treatment failure rates compared to polymyxin-based combination therapy (73\% vs $29 \% ; \mathrm{p}=0.02)$; similarly, higher treatment failure rates were seen with carbapenem monotherapy compared to carbapenem-based combination therapy (60\% vs 26\%; $p=0.03)$. Overall treatment failure rates were not significantly different in the three most common antibiotic-class combinations: polymyxin plus carbapenem, polymyxin plus tigecycline, polymyxin plus aminoglycoside (30\%, 29\%, and $25 \%$ respectively; $p=0.6$ ). In conclusion, combination therapy is recommended for the treatment of KPC infections; however, which combination of antimicrobial agents needs to be established in future prospective clinical trials.
\end{abstract}

Keywords: KPC, Treatment outcome, Klebsiella pneumoniae carbapenemases, Carbapenemase, Polymyxin, Carbapenems, Tigecycline, Aminoglycosides

\section{Introduction}

The increasing incidence of Klebsiella pneumoniae carbapenemases (KPCs) is a significant public health challenge [1]. Previously confined to sporadic outbreaks in the northeastern United States, KPCs have now spread

\footnotetext{
* Correspondence: Leeg3@uthscsa.edu

'Pharmacotherapy Education \& Research Center, School of Medicine, University of Texas Health Science Center at San Antonio, 7703 Floyd Curl Drive - MC 6220, San Antonio, TX 78229-3900, USA

${ }^{2}$ College of Pharmacy, University of Texas at Austin, 1 University Station, Austin, TX 78712, USA

Full list of author information is available at the end of the article
}

throughout the world and have reached endemic proportions in countries such as Israel and Greece [2,3]. Furthermore, KPC-producing organisms can confer resistance to multiple different antimicrobial classes, including all available $\beta$-lactams, fluoroquinolones, and aminoglycosides $[4,5]$. As such, infections due to KPCs are associated with high therapeutic failure and mortality rates of at least $50 \%[6,7]$. The limited number of agents available for the treatment of KPCs presents a tremendous challenge to clinicians. Given the lean pipeline of new antimicrobials, further investigations into optimal

\section{Biomed Central}

(c) 2012 Lee and Burgess; licensee BioMed Central Ltd. This is an Open Access article distributed under the terms of the Creative Commons Attribution License (http://creativecommons.org/licenses/by/2.0), which permits unrestricted use, distribution, and reproduction in any medium, provided the original work is properly cited. 
treatment modalities are urgently needed. However, studies on the treatment of KPC infections are scarce and mainly limited to case series and case reports. Therefore, we sought to perform a systematic review of individual cases in an effort to summarize therapeutic outcomes of various treatment regimens for KPC infections.

\section{Case selection}

A systematic review of English language articles using MEDLINE (2001-2011) was conducted. Additional studies were identified by searching bibliographies of primary articles and annual conference abstracts from 20082011. Search terms included kpc.mp, Drug Therapy/mt, mo, Treatment Outcome, Case Reports, and Disease Outbreaks/pc. All searches were limited to humans. Articles were eligible if they included patients with infections due to KPC-producing bacteria. Articles were excluded from further review if they fulfilled at least one of the following criteria: no individual patient data reported, no treatment regimen specified, no treatment outcome specified, or greater than three antibiotics or multiple antibiotic regimens directed at the KPC infection. Clinical success and failures were recorded as reported by the authors of each report. Analysis of the proportion of clinical failures was calculated as the number of failures divided by the number of treated patients. Several characteristics from the cases were extracted including the patient's age, sex, medical history, site(s) of infection, type of infection, organism, KPC subtype, APACHE II score, admission to the intensive care unit (ICU), length of stay before infection, total length of stay, minimum inhibitory concentration (MIC) of selected antimicrobials (carbapenem, polymyxin, and tigecycline), antimicrobial therapy before isolation, antimicrobial therapy directed at KPC-infection, and treatment outcome. Antimicrobial agents were categorized into the following classes: polymyxins, carbapenems, glycylcycline, aminoglycosides, cephalosporins, beta-lactam plus beta-lactamase inhibitors, fluoroquinolones, trimethoprim-sulfamethoxazole, monobactams, fosfomycin, and tetracyclines. Combination therapy was defined as at least two but no more than three, antibiotics with gram-negative activity reported to be directed at KPC infections. Statistical analysis was performed in an exploratory manner. Comparisons were made using $x^{2}$ or Fisher's exact test for categorical variables using JMP 8.0 ${ }^{\circledR}$ (SAS Corp, Cary, NC).

\section{Study characteristics}

A total of 54 relevant articles were identified searching MEDLINE, 12 from bibliographies of retrieved articles, and 61 from conference abstracts (Figure 1). Of these 127 citations, 62 articles were eligible for review for study inclusion. A total of 24 articles were excluded for the following reasons: no patient specific treatment and/ or outcomes $(n=18)$, greater than three antimicrobials $(n=4)$, and reports of colonization $(n=2)$. Within the 38 articles included, 34 individual cases were excluded for the following reasons: no patient specific treatment and/ or outcomes $(n=15)$, greater than three antimicrobials $(n=9)$, and reports of colonization $(n=10)$. A total of 38 reports comprising 105 cases met the inclusion criteria, and consisted of case series (47\%), retrospective cohort studies (35\%), and case reports (17\%). The majority of reports were from the US (42\%), followed by Greece (10\%). As expected, the number of studies reported per year increased. The majority of the articles (58\%) for this review were published in 2009 and 2011.

Several limitations should be noted. Individual studies/ reports did not always define treatment failure or treatment success. Antimicrobial dosing, procedures, residual colonization, antimicrobial timing were not always reported and therefore not considered in the outcome analysis.

\section{Characteristics of cases}

Characteristics of cases evaluated in this review are presented in Table 1 . The mean age was 62 years $\pm 19,55 \%$ were males, and $72 \%$ were admitted to the ICU. The mean APACHE II Score was $20.6 \pm 8$, the mean length of stay before infection was 17.5 days \pm 19 , while the mean total length of stay was 54.8 days \pm 40 . Infection characteristics are described in Table 2. Most of the reported infections were due to KPC-2 (86\%). Organisms largely comprised of $K$. pneumoniae (89\%), followed distantly by Pseudomonas spp (4\%), E. coli (3\%), S. marcescens $(3 \%)$, and E. cloacae (2\%). The most common site of infection was blood (52\%), followed by lung (30\%), and urine (10\%).

\section{Treatment of KPC infections}

Cases received regimens containing the following antimicrobials or antimicrobial classes: 45 cases received a polymyxin, 39 cases received a carbapenem, 30 cases received an aminoglycoside, 26 cases received a glycylcycline, 7 cases received a fluoroquinolone, 5 cases received a beta-lactam plus beta-lactamase inhibitor, 2 cases received cephalosporins, 2 cases received a tetracycline, 2 cases received a monobactam, 1 case received fosfomycin, and 1 case received trimethoprim-sulfamethoxazole. Overall, 49 (47\%) cases received monotherapy and 56 (53\%) cases received combination therapy directed at KPC-infections.

\section{Summary of treatment outcomes}

A summary of the treatment outcomes is provided in Table 3. The overall rate of treatment failure was $36 \%$ (38/105). Pulmonary infections were associated with the 


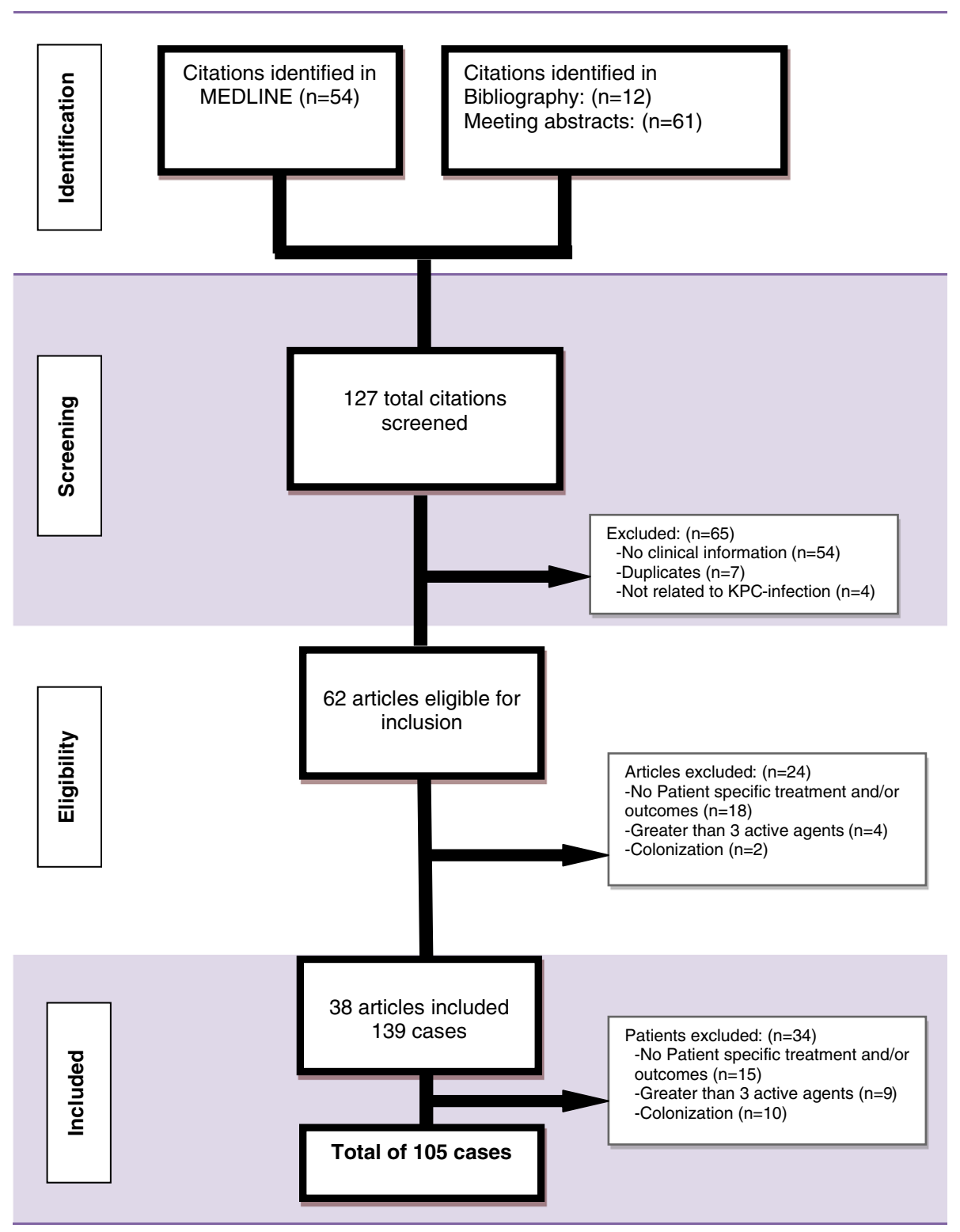

Figure 1 Case Selection.

\section{Table 1 Patient characteristics}

\begin{tabular}{lc}
\hline Characteristic & \\
\hline Age $n=88^{\mathrm{a}}$ & $62 \pm 19$ \\
Male Gender $\mathrm{n}(\%) \mathrm{n}=60^{\mathrm{a}}$ & $33(55)$ \\
ICU admission $\mathrm{n}(\%) \mathrm{n}=57^{\mathrm{a}}$ & $41(72)$ \\
APACHE II Score $\mathrm{n}=38^{\mathrm{a}}$ & $20.6 \pm 8$ \\
LOS before infection $\mathrm{n}=48^{\mathrm{a}}$ & $17.5 \pm 19$ \\
LOS, total $\mathrm{n}=24^{\mathrm{a}}$ & $54.8 \pm 40$
\end{tabular}

Abbreviations: ICU: Intensive care unit; APACHE II: Acute Physiology and Chronic Health Evaluation II; LOS: length of stay.

Data reported as mean \pm standard deviation unless otherwise noted.

${ }^{a}$ Number of study subjects for which this data were provided. highest rate of treatment failure (47\%) followed by blood infections (39\%). Of the cases with KPC infections due to Klebsiella species, 62\% (57/92) reported treatment success, 50\% (1/2) for Enterobacter cloacae, 100\% (3/3) for Serratia marcescens, and 100\% (3/3) for E. coli. Interestingly, all 4 cases of Pseudomonal KPC infections reported treatment failure. Infections with $b l a_{\mathrm{kpc}-3}$ had a higher rate of treatment failure than blakpc-2 (36\% vs. $50 \% ; \mathrm{p}=0.35)$. Pathogens harboring bla $_{\mathrm{kpc}-3}$ consisted of K. pneumoniae (12; 86\%) and Raoultella spp (2; 14\%).

\section{Polymyxins}

Polymyxin monotherapy had higher rates of treatment failure compared to polymyxin-based combination 
Table 2 Infection characteristics

\begin{tabular}{rcc}
\hline Characteristic & Data available (n) & Number of cases (\%) \\
\hline KPC-subtype & 98 & $84(86)$ \\
KPC-2 & & $14(14)$ \\
KPC-3 & 104 & \\
Organisms ${ }^{\mathrm{a}}$ & & $92(89)$ \\
K. pneumoniae & $3(3)$ \\
E. coli & & $3(3)$ \\
S. marcescens & $4(4)$ \\
Pseudomonas spp & & $2(2)$ \\
E. cloacae & & \\
Site of infection & 105 & $56(53)$ \\
Blood & & $32(31)$ \\
Pulmonary & $11(11)$ \\
Urine & $4(4)$ \\
Skin/Wound & $1(1)$ \\
Cerebral spinal fluid & $1(1)$ \\
Bone &
\end{tabular}

${ }^{a}$ Specific organism was not reported in 1 case.

${ }^{b}$ Column and row percentages may not total 100 due to rounding error.

therapy (73\% vs 29\%; $\mathrm{p}=0.02)$ [8-24]. Of the 11 cases who received polymyxin monotherapy, $73 \%$ (8/11) experienced treatment failure $[8,10,18,20,23,25]$. Of the nine patients treated for bloodstream infections (BSIs), six patients were treatment failures. Both patients treated for pneumonia with colistin monotherapy failed treatment [18]. Among cases who received polymyxinbased combination therapy, 71\% (24/34) patients had successful treatment outcomes. Of these 24 patients, the most common treatment regimen was tigecycline plus colistin (50\%), followed by carbapenem plus polymyxin (33\%) and aminoglycosides plus polymyxin (13\%). Twenty-nine percent of patients (10/34) who received polymyxin-based combination therapy experienced treatment failure. Five patients were treated for BSIs with the following regimens: carbapenem plus colistin (3), tigecycline plus colistin (1), and amikacin plus colistin (1)

Table 3 Overall treatment outcome

\begin{tabular}{|c|c|c|}
\hline & Data available & Treatment outcome (\%) \\
\hline Overall treatment failure & 105 & $38 / 105(36)$ \\
\hline Source (failure) & 105 & \\
\hline Blood & & 22/56(39) \\
\hline Pulmonary & & $15 / 32(47)$ \\
\hline Urine & & $1 / 11(9)$ \\
\hline KPC-type & 98 & \\
\hline KPC-2 & & $30 / 84(36)$ \\
\hline KPC-3 & & $7 / 14(50)$ \\
\hline
\end{tabular}

$[8,9,12]$. In the latter case, the patient developed colistin resistance (MIC $0.25 \mu \mathrm{g} / \mathrm{mL}$ to $16 \mu \mathrm{g} / \mathrm{mL}$ ) while on treatment and eventually died. The other five cases of treatment failure consisted of cases of pulmonary infection treated with the following antimicrobials in combination with a polymyxin: tigecycline (3), carbapenem (1), and fluoroquinolone (1) $[8,11,16,26]$.

Although polymyxins were the most commonly used antimicrobial against KPC infections in this review, the effectiveness of polymyxins for the treatment of KPC infections is not well established. Various in-vitro studies have demonstrated bactericidal activity and synergy when polymyxins are tested in combination with carbapenems, rifampin or tigecycline, while monotherapy often led to significant re-growth by 24 hours [27-29]. Furthermore, a report by Lee and colleagues [30] evaluated 12 patients with persistent blood cultures positive for KPC-K. pneumoniae despite 3 days of treatment with either polymyxin B alone or polymyxin B plus tigecycline. Interestingly, 3 of the 12 patients who received polymyxin B monotherapy had significant increases in MIC values $(1.5 \mu \mathrm{g} / \mathrm{mL}$ to $32 \mu \mathrm{g} / \mathrm{mL}, 0.75 \mu \mathrm{g} / \mathrm{mL}$ to 12 $\mu \mathrm{g} / \mathrm{mL}$, and $0.75 \mu \mathrm{g} / \mathrm{mL}$ to $1024 \mu \mathrm{g} / \mathrm{mL}$ ) while none of the patients who received polymyxin $\mathrm{B}$ in combination with tigecycline developed resistance. The authors hypothesized that combination therapy may have prevented resistance in patients who received both polymyxin B and tigecycline. Similar reports of gram negative organisms developing resistance to colistin have been described [31-33]. Polymyxins are one of the few antimicrobial classes that remain susceptible to KPCproducing organisms. Increasing reports of polymyxin resistance described in case reports and recent outbreaks of polymyxin-resistant strains are troubling [33-39]. Combination therapy may be an important strategy for the management of KPC infections when utilizing polymyxins. However, determining which antimicrobial in combination with polymyxins is superior still needs to be established in further clinical studies.

\section{Carbapenems}

Of the 39 cases who received a carbapenem, 51\% (20/39) received carbapenem monotherapy and 49\% (19/39) received carbapenem-based combination therapy $[8,14$, 16,17,40-50]. Carbapenem monotherapy had higher rates of treatment failure compared to carbapenem-based combination therapy (60\% versus $26 \% \mathrm{p}=0.03)$. Of the $20 \mathrm{ca}-$ ses who received carbapenem monotherapy, 55\% (11/20) failed treatment, including 6 cases with strains having MICs $\leq 4 \mu \mathrm{g} / \mathrm{mL}$ (previous CLSI breakpoint for imipenem and meropenem). The majority of those who failed treatment had pneumonia or tracheobronchitis (7), followed by BSI (3), and urinary tract infection (UTI) (1) $[40,43,48,49]$. Among cases who received carbapenem- 
based combination therapy, $74 \%$ of patients (14/19) had successful treatment outcomes. In these 14 patients, the most common treatment regimen was polymyxin plus carbapenem (8), followed by aminoglycoside plus carbapenem (4), and beta-lactam plus beta-lactamase inhibitor plus carbapenem (2). A total of 5 patients receiving carbapenem-based combination therapy experienced treatment failure. All but one of these 5 patients were treated with a carbapenem plus polymyxin.

Several issues regarding the use of carbapenems for the treatment of KPC-infections should be considered. Nine of the cases who received carbapenem monotherapy were reported from one retrospective case series [40]. In the retrospective review, patients infected with imipenem non-susceptible KPC K. pneumoniae $(\mathrm{MIC}>4 \mu \mathrm{g} / \mathrm{mL}$ ) treated with alternative therapies had a higher rate of successful treatment $(8 / 10,80 \%)$ when compared with patients infected with imipenem-susceptible (MIC $\leq 4$ $\mu \mathrm{g} / \mathrm{mL}$ ) KPC K. pneumoniae treated with a carbapenem (4/9, 44.4\%). The optimal pharmacodynamic parameter for carbapenems is the time the free carbapenem concentration remains above the MIC (\%T > MIC) [51]; however, whether this parameter is valid in the presence of KPCs is controversial. In a mouse thigh infection model, Craig et al. [52] demonstrated that the presence of KPCs had no impact on achieving pharmacodynamic parameters of strains with MICs up to $16 \mu \mathrm{g} / \mathrm{mL}$. There has been only one case report describing the successful use of high-dose continuous infusion meropenem monotherapy for a carbapenem non-susceptible KPC K. pneumoniae (MIC $=8$ $\mu \mathrm{g} / \mathrm{mL}$ ) BSI [50]. In contrast, an in vitro model, simulating human exposure to a high-dose prolonged-infusion meropenem ( 2 g every $8 \mathrm{~h}$ over 3 -hr infusion), demonstrated that the killing activity at 24 hours, against KPCproducing $K$. pneumoniae strains, were inferior to non-carbapenemase-producing Pseudomonas aeruginosa strains despite similar meropenem MICs [53]. The authors attributed this to the rapid in-vitro hydrolysis of meropenem, resulting in lower exposure of meropenem to the KPC K. pneumoniae. The Clinical and Laboratory Standards Institute (CLSI) recently lowered clinical breakpoints of carbapenems to exclude KPC-producing organisms in the previous susceptible range [54]. Susceptibilities to imipenem, meropenem and doripenem have been defined by an MIC up to $1 \mu \mathrm{g} / \mathrm{mL}$ and $0.5 \mu \mathrm{g} / \mathrm{mL}$ for ertapenem. The utility of carbapenem monotherapy against strains containing KPCs remains controversial. Until further data are available, the use of combination or alternative therapy may be warranted.

\section{Tigecycline}

Of the 26 cases who received tigecycline, 7 cases received tigecycline monotherapy and 19 received tigecyclinebased combination therapy $[8,9,11,12,17,26,40,41,47,55,56]$.
There was no significant difference in treatment failure rates between cases receiving tigecycline monotherapy compared to those receiving combination therapy (29\% vs. $37 \%$; $=0.4)$. Twenty-nine percent $(2 / 7)$ of patients who received tigecycline monotherapy experienced treatment failure. One patient was treated for urosepsis and the other was treated for nosocomial pneumonia and empyema $[40,56]$. In the latter, even though a long course of tigecycline resolved the pneumonia, treatment was complicated by recurrence of empyema associated with an increase in tigecycline MIC from 0.75 to $2 \mu \mathrm{g} / \mathrm{mL}$. Of the 19 patients who received tigecycline combination therapy, 14 (74\%) received polymyxin plus tigecycline, 3 (16\%) received tigecycline plus aminoglycoside, and 2 (11\%) received tigecycline plus carbapenem. Both patients who received tigecycline plus a carbapenem experienced treatment failures [40,41]. In one report, despite a month-long course of tigecycline and meropenem for KPC-K. pneumoniae bacteremia secondary to sclerosing cholangitis, the patient experienced relapse of the bacteremia which was associated with the development of resistance to both meropenem and tigecycline [41].

Tigecycline has demonstrated excellent spectrum of activity against KPC-producing organisms. In a collection of 106 carbapenemase-producing strains from various countries, tigecycline was the only antimicrobial with $100 \%$ activity [5]. However, there are no breakpoints set by the CLSI for tigecycline for Enterobacteriaceae (FDAapproved breakpoint for tigecycline is $<2 \mu \mathrm{g} / \mathrm{mL})$. In addition, tigecycline has limited activity against Pseudomonas species. Clinical issues with tigecycline's pharmacokinetic properties may raise some caution in treatment of UTIs and BSIs due to low urinary $(<22 \%)$ and low plasma $(\leq 0.9 \mathrm{mg} / \mathrm{L})$ concentrations $[57,58]$. However, tigecycline has been used successfully in treating these infections; both patients included in this review who were treated with tigecycline monotherapy for their UTIs, were treated successfully [40,59]. In contrast, in an evaluation of 48 patients with carbapenem-resistant $K$. pneumoniae bacteremia in a tertiary care hospital, all 8 patients with break-through bacteremias had received tigecycline [60] reports of tigecycline resistance have been previously demonstrated in Enterobacteriaceae [56,61-63]. Finally, tigecycline is a bacteriostatic agent; thus, alternative agents or combination therapy may be required for infections requiring bactericidal activity.

\section{Aminoglycosides}

A total of 30 cases received an aminoglycoside, 20\% (6/30) of cases as monotherapy and 80\% (24/30) as combination therapy $[8-13,16,19,22,40,42,47,48,55,64-68]$. There was no significant difference in treatment failure rates between those who received aminoglycoside monotherapy compared to combination therapy ( $0 \%$ vs. $17 \%$; $\mathrm{p}=0.6)$. 
Interestingly, all six cases who received aminoglycoside monotherapy reported success: three cases were treated for BSIs, two cases were treated for UTIs, and one case was treated for a respiratory infection [11,13,40,64]. A recent study demonstrated that aminoglycosides, when active in vitro, were associated with a significantly higher rate of microbiologic clearance of carbapenem-resistant $K$. pneumoniae in the urine compared to polymyxin B or tigecycline [69]. Of the patients who received aminoglycoside-based combination therapy, the most common treatment was amikacin plus colistin (11), followed by aminoglycoside plus a carbapenem (4), aminoglycoside plus a fluoroquinolone (5), aminoglycoside plus tigecycline (2), gentamicin plus aztreonam (1), and amikacin plus tetracycline (1). Despite in-vitro evidence of antagonism when using polymyxins and aminoglycosides in combination, 6 clinical cases of polymyxin plus an aminoglycoside reported treatment success [11,19,22,65]. All patients who failed therapy with aminoglycoside-based therapy had BSIs. One reported case had bacteremia due to KPC-2-producing E. cloacae and P. putida recovered simultaneously from multiple cultures; the patient eventually died [68]. Herein, the most commonly employed aminoglycoside combination was amikacin plus colistin; but, the potential increased risk of nephrotoxicity with this combination is a major concern.

\section{Combination versus monotherapy}

Of all cases meeting the study inclusion criteria, 49 (47\%) cases received monotherapy and 56 (53\%) cases received combination therapy directed at KPC-infections. Significantly more treatment failures were seen in cases treated with monotherapy than those treated with combination therapy ( $49 \%$ vs. $25 \%$; $\mathrm{p}=0.01)$ (Table 4$)$. Similar treatment failure rates were observed in the three most common antibiotic-class combinations: polymyxin plus a carbapenem, polymyxin plus tigecycline, polymyxin plus an aminoglycoside (30\%, $29 \%$, and $25 \%$

Table 4 Treatment failure: Monotherapy vs. Combination therapy

\begin{tabular}{|c|c|c|c|}
\hline & $\begin{array}{c}\text { Monotherapy } \\
\text { (\%) }\end{array}$ & $\begin{array}{c}\text { Combination } \\
(\%)\end{array}$ & $P$ \\
\hline Overall treatment failure & 24/49(49) & $14 / 56(25)$ & 0.01 \\
\hline \multicolumn{4}{|l|}{ Source: } \\
\hline Blood & $12 / 24(50)$ & 9/32(28) & 0.09 \\
\hline Pulmonary & $10 / 15(67)$ & $5 / 17(29)$ & 0.03 \\
\hline Urine & $1 / 8(13)$ & $0 / 3(0)$ & 0.4 \\
\hline Polymyxin treatment failure & $8 / 11(73)$ & 10/34(29) & 0.02 \\
\hline Carbapenem treatment failure & $12 / 20(60)$ & $5 / 19(26)$ & 0.03 \\
\hline Tigecycline treatment failure & $2 / 7(29)$ & 7/19(37) & 0.4 \\
\hline Aminoglycoside treatment failure & $0 / 6(0)$ & $4 / 24(17)$ & 0.6 \\
\hline
\end{tabular}

respectively; $\mathrm{p}=0.6$ ). In three cases, triple antimicrobial therapy directed at the KPC infection was used: one case received doripenem plus polymyxin $\mathrm{B}$ plus rifampin and 2 cases received tigecycline plus colistin plus garamycin $[11,17]$. All three cases were treated successfully.

A review of treatment outcomes versus sites of infection showed urinary sources of infection had the highest overall treatment success rates of $81 \%(9 / 11)$. A recent retrospective cohort study of 21 patients with UTIs described similar positive clinical responses in 16 (76\%) patients [70]. Of the 11 patients who were treated for UTIs in this review, the majority were treated with monotherapy (8/11), and of these patients, only one experienced treatment failure while on imipenem $(\mathrm{MIC}=4 \mu \mathrm{g} / \mathrm{mL})[40]$. The eight cases treated successfully with monotherapy received either a carbapenem (3), tigecycline (2), an aminoglycoside (1), ciprofloxacin (1) or cefepime $(1)[8,16]$. All 3 cases treated with combination therapy for UTIs reported treatment success. The pulmonary site of infection was associated with higher rates of treatment failure with monotherapy compared to combination therapy (67\% vs. $29 \% \mathrm{p}=0.03)$. Among the 17 patients with pulmonary infections treated successfully, more than $75 \%$ of cases received combination therapy. The most common regimen for the successful treatment of pulmonary infections consisted of tigecycline plus colistin (8), followed by an aminoglycoside plus colistin (3). Likewise, there was a lower failure rate treating blood-stream infections with combination therapy compared to monotherapy, (28\% vs. $50 \% ; \mathrm{p}=0.09$ ).

Several recent studies have supported the role of combination therapy for treating KPC infections. In a cohort of 41 patients with KPC- K. pneumoniae bacteremia, the use of combination therapy was associated with improved 28-day mortality [71]. The most common successful combination employed in this cohort was a polymyxin in combination with either tigecycline or a carbapenem. Tumbarello et al. [72] conducted a study in three Italian hospitals and demonstrated that combination therapy, particularly a triple-drug regimen including tigecycline, colistin, plus a carbapenem, was independently associated with improved survival. Likewise, in a previous pool of 55 individual cases, combination therapy was associated with successful outcomes compared to monotherapy, particularly if polymyxins were part of the regimen [73].

\section{Conclusion}

Infections caused by KPC-producing bacteria have been associated with high mortality rates and frequent treatment failure. Clinical data on treatment are limited and appropriate therapy for KPC infections is not well defined. This review demonstrated that monotherapy is 
associated with higher treatment failure rates compared to combination therapy when managing infections due to KPC-producing bacteria, particularly when treating respiratory infections. Polymyxins and carbapenems when used alone were associated with higher treatment failure than when used in combination. Until further data are available, combination therapy is recommended. However, which antimicrobial combination is superior has yet to be established.

\section{Competing interests}

The authors declare that they have no competing interests.

\section{Authors' contributions}

$\mathrm{GL}$ carried out the systematic review, performed the analysis, and drafted the manuscript. DB participated in the design and helped to draft the manuscript. Both authors read and approved the final manuscript

\section{Acknowledgements}

We thank Dr. Leroy Knodel for his thoughtful and thorough review of the manuscript and Dr. Eugene Kreys for assisting in editing and formatting.

\section{Author details}

${ }^{1}$ Pharmacotherapy Education \& Research Center, School of Medicine, University of Texas Health Science Center at San Antonio, 7703 Floyd Curl Drive - MC 6220, San Antonio, TX 78229-3900, USA. ${ }^{2}$ College of Pharmacy, University of Texas at Austin, 1 University Station, Austin, TX 78712, USA. ${ }^{3}$ Department of Pharmacy Practice and Science, University of Kentucky College of Pharmacy, 789 S. Limestone, 292K, Lexington, KY 40536, USA.

Received: 26 September 2012 Accepted: 9 December 2012 Published: 13 December 2012

\section{References}

1. Gaynes RP, Culver DH: Resistance to imipenem among selected gramnegative bacilli in the United States. Infect Control Hosp Epidemiol 1992, 13(1):10-14.

2. Yigit H, Queenan AM, Anderson GJ, Domenech-Sanchez A, Biddle JW, Steward CD, Alberti S, Bush K, Tenover F: Novel carbapenem-hydrolyzing beta-lactamase, KPC-1, from a carbapenem-resistant strain of Klebsiella pneumoniae. Antimicrob Agents Chemother 2001, 45(4):1151-1161.

3. Arnold RS, Thom KA, Sharma S, Phillips M, Kristie Johnson J, Morgan DJ: Emergence of Klebsiella pneumoniae carbapenemase-producing bacteria. South Med J 2011, 104(1):40-45.

4. Endimiani A, Hujer AM, Perez F, Bethel CR, Hujer KM, Kroeger J, Oethinger M, Paterson D, Adams M, Jacobs M, Diekema D, Hall G, Jenkins S, Rice L, Tenover F, Bonomo R: Characterization of blaKPC-containing Klebsiella pneumoniae isolates detected in different institutions in the eastern USA. J Antimicrob Chemother 2009, 63(3):427-437.

5. Castanheira M, Sader HS, Deshpande LM, Fritsche TR, Jones RN: Antimicrobial activities of tigecycline and other broad-spectrum antimicrobials tested against serine carbapenemase- and metallo-betalactamase-producing enterobacteriaceae: Report from the SENTRY antimicrobial surveillance program. Antimicrob Agents Chemother 2008, 52(2):570-573.

6. Bratu S, Landman D, Haag R, Recco R, Eramo A, Alam M, Quale J: Rapid spread of carbapenem-resistant Klebsiella pneumoniae in New York City: A new threat to our antibiotic armamentarium. Arch Intern Med 2005, 165(12):1430-1435

7. Gasink LB, Edelstein PH, Lautenbach E, Fishman NO: Risk factors and clinical impact of Klebsiella pneumoniae carbapenemase-producing $\mathrm{K}$. pneumoniae. Infect Control Hosp Epidemiol 2009, 30(12):1180-1185.

8. Souli M, Galani I, Antoniadou A, Papadomichelakis E, Poulakou G, Panagea T, Vourli S, Zerva L, Armaganidis A, Kanellakopoulou K, Giamarellou H: An outbreak of infection due to beta-lactamase Klebsiella pneumoniae carbapenemase 2-producing $K$. pneumoniae in a Greek university hospital: Molecular characterization, epidemiology, and outcomes. Clin Infect Dis 2010, 50(3):364-373.
9. Steinmann J, Kaase M, Gatermann S, Popp W, Steinmann E, Damman M, Paul A, Saner F, Buer J, Rath P: Outbreak due to a Klebsiella pneumoniae strain harbouring KPC-2 and VIM-1 in a German university hospital, July 2010 to January 2011. Euro Surveill 2011, 16(33):19944.

10. Nadkarni AS, Schliep T, Khan L, Zeana CB: Cluster of bloodstream infections caused by KPC-2 carbapenemase-producing Klebsiella pneumoniae in Manhattan. Am J Infect Control 2009, 37(2):121-126.

11. Maltezou HC, Giakkoupi P, Maragos A, Bolikas M, Raftopoulos V, Papahatzaki $H$, Vrouhos G, Liakou V, Vatopoulos A: Outbreak of infections due to KPC-2-producing Klebsiella pneumoniae in a hospital in Crete (Greece). J Infect 2009, 58(3):213-219.

12. Babouee B, Widmer AF, Dubuis O, Ciardo D, Droz S, Betsch BY, Garzoni C, Fuhrer U, Battegay M, Frei R, Goldenberger D: Emergence of four cases of KPC-2 and KPC-3-carrying Klebsiella pneumoniae introduced to Switzerland, 2009-10. Bull Europeen European Commun Dis Bull 2011, 16(11). pii=19817. Available online: http://www.eurosurveillance.org/ ViewArticle.aspx?Articleld=19817.

13. Tsakris A, Themeli-Digalaki K, Poulou A, Vrioni G, Voulgari E, Koumaki V, Agodi A, Pournaras S, Sofianou D: Comparative evaluation of combineddisk tests using different boronic acid compounds for detection of Klebsiella pneumoniae carbapenemase-producing enterobacteriaceae clinical isolates. J Clin Microbiol 2011, 49(8):2804-2809.

14. Hirsch EB, Chang KT, Lasco TM, Caeiro JP, Tam VH: Emergence of KPCproducing Klebsiella pneumoniae in Texas. Diagn Microbiol Infect Dis 2011, 69(2):234-235.

15. Chung KP, Tseng SP, Huang YT, Tsai TH, Teng LJ, Hsueh PR: Arrival of Klebsiella pneumoniae carbapenemase (KPC)-2 in Taiwan. J Antimicrob Chemother 2011, 66(5):1182-1184.

16. Bradford PA, Bratu S, Urban C, Visalli M, Mariano N, Landman D, Rahal JJ, Brooks S, Cebular S, Quale J: Emergence of carbapenem-resistant Klebsiella species possessing the class A carbapenem-hydrolyzing KPC-2 and inhibitor-resistant TEM-30 beta-lactamases in New York City. Clin Infect Dis 2004, 39(1):55-60.

17. Gomez-Gil MR, Pano-Pardo JR, Romero-Gomez MP, Gasior M, Lorenzo M, Quiles I, Mingorance J: Detection of KPC-2-producing Citrobacter freundii isolates in Spain. J Antimicrob Chemother 2010, 65(12):2695-2697.

18. Villegas MV, Lolans K, Correa A, Kattan JN, Lopez JA, Quinn JP, Colombian Nosocomial Resistance Study Group: First identification of Pseudomonas aeruginosa isolates producing a KPC-type carbapenem-hydrolyzing betalactamase. Antimicrob Agents Chemother 2007, 51(4):1553-1555.

19. Naas T, Cuzon G, Babics A, Fortineau N, Boytchev I, Gayral F, Nordmann P: Endoscopy-associated transmission of carbapenem-resistant Klebsiella pneumoniae producing KPC-2 beta-lactamase. J Antimicrob Chemother 2010, 65(6):1305-1306.

20. Barbier F, Ruppe E, Giakkoupi P, Wildenberg L, Lucet J, Vatopoulos A, Wolff M, Andremont A: Genesis of a KPC-producing Klebsiella pneumoniae after in vivo transfer from an imported Greek strain. Bull Europeen European Commun Dis Bull 2010, 15(1). pii=19457. Available online:http//www. eurosurveillance.org/NiewArticle.aspx?Articleid=19457.

21. Sidjabat HE, Silveira FP, Potoski BA, Abu-Elmagd KM, Adams-Haduch JM, Paterson DL, Doi Y: Interspecies spread of Klebsiella pneumoniae carbapenemase gene in a single patient. Clin Infect Dis 2009, 49(11):1736-1738.

22. Benenson S, Navon-Venezia S, Carmeli Y, Adler A, Strahilevitz J, Moses AE, Block C: Carbapenem-resistant Klebsiella pneumoniae endocarditis in a young adult. successful treatment with gentamicin and colistin. Int J Infect Dis 2009, 13(5):e295-e298.

23. Beirao EM, Furtado JJ, Girardello R, Ferreira Filho H, Gales AC: Clinical and microbiological characterization of KPC-producing Klebsiella pneumoniae infections in Brazil. Braz J Infect Dis 2011, 15(1):69-73.

24. Mathers AJ, Cox HL, Bonatti H, Kitchel B, Brassinga AK, Wispelwey B, Sawyer $R G$, Pruett $T L$, Hazen KC, Patel JB, Sifri CD: Fatal cross infection by carbapenem-resistant Klebsiella in two liver transplant recipients. Transpl Infect Dis 2009, 11(3):257-265.

25. Endimiani A, Depasquale JM, Forero S, Perez F, Hujer AM, Roberts-Pollack D, Fiorella PD, Pickens N, Kitchel B, Casiano-Colon AE, Tenover FC, Bonomo RA: Emergence of blaKPC-containing Klebsiella pneumoniae in a long-term acute care hospital: A new challenge to our healthcare system. J Antimicrob Chemother 2009, 64(5):1102-1110.

26. Lopez JA, Correa A, Navon-Venezia S, Correa AL, Torres JA, Briceno DF, Montealegre MC, Quinn JP, Carmeli Y, Villegas MV: Intercontinental spread 
from Israel to Colombia of a KPC-3-producing Klebsiella pneumoniae strain. Clin Microbiol Infect 2011, 17(1):52-56.

27. Pournaras S, Vrioni G, Neou E, Dendrinos J, Dimitroulia E, Poulou A, Tsakris A: Activity of tigecycline alone and in combination with colistin and meropenem against Klebsiella pneumoniae carbapenemase (KPC)producing enterobacteriaceae strains by time-kill assay. Int J Antimicrob Agents 2011, 37(3):244-247.

28. Bratu S, Tolaney P, Karumudi U, Quale J, Mooty M, Nichani S, Landman D: Carbapenemase-producing Klebsiella pneumoniae in Brooklyn, NY: Molecular epidemiology and in vitro activity of polymyxin $B$ and other agents. J Antimicrob Chemother 2005, 56(1):128-132.

29. Pankey GA, Ashcraft DS: Detection of synergy using the combination of polymyxin $B$ with either meropenem or rifampin against carbapenemase-producing Klebsiella pneumoniae. Diagn Microbiol Infect Dis 2011, 70(4):561-564.

30. Lee J, Patel G, Huprikar S, Calfee DP, Jenkins SG: Decreased susceptibility to polymyxin B during treatment for carbapenem-resistant Klebsiella pneumoniae infection. J Clin Microbiol 2009, 47(5):1611-1612.

31. Falagas ME, Rafailidis PI, Ioannidou E, Alexiou VG, Matthaiou DK, Karageorgopoulos DE, Kapaskelis A, Nikita D, Michalopoulos A: Colistin therapy for microbiologically documented multidrug-resistant gramnegative bacterial infections: A retrospective cohort study of 258 patients. Int J Antimicrob Agents 2010, 35(2):194-199.

32. Samonis G, Matthaiou DK, Kofteridis D, Maraki S, Falagas ME: In vitro susceptibility to various antibiotics of colistin-resistant gram-negative bacterial isolates in a general tertiary hospital in Crete, Greece. Clin Infect Dis 2010, 50(12):1689-1691.

33. Matthaiou DK, Michalopoulos A, Rafailidis PI, Karageorgopoulos DE, Papaioannou V, Ntani G, Samonis G, Falagas ME: Risk factors associated with the isolation of colistin-resistant gram-negative bacteria: A matched case-control study. Crit Care Med 2008, 36(3):807-811.

34. Toth A, Damjanova I, Puskas E, Janvari L, Farkas M, Dobak A, Borocz K, Paszti J. Emergence of a colistin-resistant KPC-2-producing Klebsiella pneumoniae ST258 clone in Hungary. Eur J Clin Microbiol Infect Dis 2010, 29(7):765-769.

35. Zarkotou O, Pournaras S, Voulgari E, Chrysos G, Prekates A, Voutsinas D, Themeli-Digalaki K, Tsakris A: Risk factors and outcomes associated with acquisition of colistin-resistant KPC-producing Klebsiella pneumoniae: A matched case-control study. J Clin Microbiol 2010, 48(6):2271-2274.

36. Humphries RM, Kelesidis T, Dien Bard J, Ward KW, Bhattacharya D, Lewinski MA: Successful treatment of pan-resistant Klebsiella pneumoniae pneumonia and bacteraemia with a combination of high-dose tigecycline and colistin. J Med Microbiol 2010, 59:1383-1386.

37. Neonakis IK, Samonis G, Messaritakis H, Baritaki S, Georgiladakis A, Maraki S, Spandidos DA: Resistance status and evolution trends of Klebsiella pneumoniae isolates in a university hospital in Greece: Ineffectiveness of carbapenems and increasing resistance to colistin. Chemotherapy 2010, 56(6):448-452

38. Bogdanovich T, Adams-Haduch JM, Tian GB, Nguyen MH, Kwak EJ, Muto CA, Doi Y: Colistin-resistant, Klebsiella pneumoniae carbapenemase (KPC)producing Klebsiella pneumoniae belonging to the international epidemic clone ST258. Clin Infect Dis 2011, 53(4):373-376.

39. Jernigan MG, Press EG, Nguyen MH, Clancy CJ, Shields RK: The combination of doripenem and colistin is bactericidal and synergistic against colistinresistant, carbapenemase-producing Klebsiella pneumoniae. Antimicrob Agents Chemother 2012, 56(6):3395-3398.

40. Weisenberg SA, Morgan DJ, Espinal-Witter R, Larone DH: Clinical outcomes of patients with Klebsiella pneumoniae carbapenemase-producing $\mathrm{K}$. pneumoniae after treatment with imipenem or meropenem. Diagn Microbiol Infect Dis 2009, 64(2):233-235.

41. Goldfarb D, Harvey SB, Jessamine K, Jessamine P, Toye B, Desjardins M: Detection of plasmid-mediated KPC-producing Klebsiella pneumoniae in Ottawa, Canada: Evidence of intrahospital transmission. J Clin Microbiol 2009, 47(6):1920-1922.

42. Leao RS, Carvalho-Assef AP, Correal JC, Silva RV, Goldemberg DC, Asensi MD, Marques EA: KPC-2 producing Klebsiella pneumoniae and Escherichia coli co-infection in a catheter-related infection. Clin Microbiol Infect 2011, 17(3):380-382

43. Rhee JY, Park YK, Shin JY, Choi JY, Lee MY, Peck KR, Song JH, Ko KS: KPC producing extreme drug-resistant Klebsiella pneumoniae isolate from a patient with diabetes mellitus and chronic renal failure on hemodialysis in South Korea. Antimicrob Agents Chemother 2010, 54(5):2278-2279.
44. Akpaka PE, Swanston WH, Ihemere HN, Correa A, Torres JA, Tafur JD, Montealegre MC, Quinn JP, Villegas MV: Emergence of KPC-producing Pseudomonas aeruginosa in Trinidad and Tobago. J Clin Microbiol 2009, 47(8):2670-2671.

45. Mendes RE, Bell JM, Turnidge JD, Yang Q, Yu Y, Sun Z, Jones RN Carbapenem-resistant isolates of Klebsiella pneumoniae in china and detection of a conjugative plasmid (blaKPC-2 plus qnrB4) and a blalMP-4 gene. Antimicrob Agents Chemother 2008, 52(2):798-799.

46. Villegas MV, Lolans K, Correa A, Suarez CJ, Lopez JA, Vallejo M, Quinn JP, Colombian Nosocomial Resistance Study Group: First detection of the plasmid-mediated class A carbapenemase KPC-2 in clinical isolates of Klebsiella pneumoniae from South America. Antimicrob Agents Chemother 2006, 50(8):2880-2882.

47. Le J, Castanheira M, Burgess DS, McKee B, lqbal R, Jones RN: Clonal dissemination of Klebsiella pneumoniae carbapenemase KPC-3 in Long Beach, California. J Clin Microbiol 2010, 48(2):623-625.

48. Endimiani A, Carias LL, Hujer AM, Bethel CR, Hujer KM, Perez F, Hutton RA Fox WR, Hall GS, Jacobs MR, Paterson DL, Rice LB, Jenkins SG, Tenover FC, Bonomo RA: Presence of plasmid-mediated quinolone resistance in Klebsiella pneumoniae isolates possessing blaKPC in the United States. Antimicrob Agents Chemother 2008, 52(7):2680-2682.

49. Wei Z, Yu T, Qi Y, Ji S, Shen P, Yu Y, Chen Y: Coexistence of plasmidmediated KPC-2 and IMP-4 carbapenemases in isolates of Klebsiella pneumoniae from China. J Antimicrob Chemother 2011, 66(11):2670-2671.

50. Ho VP, Jenkins SG, Afaneh Cl, Turbendian HK, Nicolau DP, Barie PS: Use of meropenem by continuous infusion to treat a patient with a bla(kpc-2) positive Klebsiella pneumoniae blood stream infection. Surg Infect 2011, 12(4):325-327

51. Perrott J, Mabasa VH, Ensom MH: Comparing outcomes of meropenem administration strategies based on pharmacokinetic and pharmacodynamic principles: A qualitative systematic review. Ann Pharmacother 2010, 44(3):557-564.

52. Craig WA, Kethireddy S, Andes DR, Stamstad T, Marchilo K, Jones RN: Impact of KPCs on the in vivo activity of three carbapenems in the neutropenic mouse-thigh infection model [abstract]. 46th Interscience Conference Antimicrobial and Agents Chemotherapy (ICAAC). Washington, DC: American Society for Microbiology and Infectious Diseases Society of America; 2008.

53. Bulik CC, Christensen H, Li P, Sutherland CA, Nicolau DP, Kuti JL: Comparison of the activity of a human simulated, high-dose, prolonged infusion of meropenem against Klebsiella pneumoniae producing the KPC carbapenemase versus that against Pseudomonas aeruginosa in an in vitro pharmacodynamic model. Antimicrob Agents Chemother 2010, 54(2):804-810.

54. Clinical and Laboratory Standards Institute (CLSI): Performance standards for antimicrobial susceptibility testing: twentieth informational supplement (June 2010 update). CLSI document M100-S20-U. Wayne, PA, USA: Clinical and Laboratory Standards Institute; 2010.

55. Tsakris A, Voulgari E, Poulou A, Kimouli M, Pournaras S, Ranellou K, Kosmopoulou O, Petropoulou D: In vivo acquisition of a plasmidmediated bla(KPC-2) gene among clonal isolates of Serratia marcescens. J Clin Microbiol 2010, 48(7):2546-2549.

56. Daly MW, Riddle DJ, Ledeboer NA, Dunne WM, Ritchie DJ: Tigecycline for treatment of pneumonia and empyema caused by carbapenemaseproducing Klebsiella pneumoniae. Pharmacotherapy 2007, 27(7):1052-1057.

57. Peleg AY, Potoski BA, Rea R, Adams J, Sethi J, Capitano B, Husain S, Kwak EJ, Bhat SV, Paterson DL: Acinetobacter baumannii bloodstream infection while receiving tigecycline: A cautionary report. J Antimicrob Chemother 2007, 59(1):128-131.

58. Meagher AK, Ambrose PG, Grasela TH, Ellis-Grosse EJ: The pharmacokinetic and pharmacodynamic profile of tigecycline. Clin Infect Dis 2005 41(Suppl 5):S333-S340.

59. Le J, McKee B, Srisupha-Olarn W, Burgess DS: In vitro activity of carbapenems alone and in combination with amikacin against KPCproducing Klebsiella pneumoniae. J Clin Med Res 2011, 3(3):106-110.

60. Nguyen M, Eschenauer GA, Bryan M, O'Neil K, Furuya EY, Della-Latta P, Kubin CJ: Carbapenem-resistant Klebsiella pneumoniae bacteremia: Factors correlated with clinical and microbiologic outcomes. Diagn Microbiol Infect Dis 2010, 67(2):180-184.

61. Kelesidis T, Karageorgopoulos DE, Kelesidis I, Falagas ME: Tigecycline for the treatment of multidrug-resistant enterobacteriaceae: A systematic review of the evidence from microbiological and clinical studies. J Antimicrob Chemother 2008, 62(5):895-904. 
62. Hussein $\mathrm{K}$, Sprecher $\mathrm{H}$, Mashiach $\mathrm{T}$, Oren I, Kassis I, Finkelstein R: Carbapenem resistance among Klebsiella pneumoniae isolates: Risk factors, molecular characteristics, and susceptibility patterns. Infect Control Hosp Epidemiol 2009, 30(7):666-671.

63. Elemam A, Rahimian J, Mandell W: Infection with panresistant Klebsiella pneumoniae: A report of 2 cases and a brief review of the literature. Clin Infect Dis 2009, 49(2):271-274.

64. Richter SN, Frasson I, Bergo C, Parisi S, Cavallaro A, Palu G: Transfer of KPC2 carbapenemase from Klebsiella pneumoniae to Escherichia coli in a patient: First case in Europe. J Clin Microbiol 2011, 49(5):2040-2042.

65. Bratu S, Brooks S, Burney S, Kochar S, Gupta J, Landman D, Quale J: Detection and spread of Escherichia coli possessing the plasmid-borne carbapenemase KPC-2 in Brooklyn, New York. Clin Infect Dis 2007, 44(7):972-975.

66. Lo A, Verrall R, Williams J, Stratton C, Della-Latta P, Tang YW: Carbapenem resistance via the blaKPC-2 gene in Enterobacter cloacae blood culture isolate. South Med J 2010, 103(5):453-454.

67. Kuai S, Huang L, Pei H, Chen Y, Liu J: Imipenem resistance due to class A carbapenemase KPC-2 in a Flavobacterium odoratum isolate. J Med Microbiol 2011, 60:1408-1409.

68. Bennett JW, Mende K, Herrera ML, Yu X, Lewis JS 2nd, Wickes BL, Jorgensen $\mathrm{JH}$, Murray CK: Mechanisms of carbapenem resistance among a collection of enterobacteriaceae clinical isolates in a Texas city. Diagn Microbiol Infect Dis 2010, 66(4):445-448.

69. Satlin MJ, Kubin CJ, Blumenthal JS, Cohen AB, Furuya EY, Wilson SJ, Jenkins SG, Calfee DP: Comparative effectiveness of aminoglycosides, polymyxin B, and tigecycline for clearance of carbapenem-resistant Klebsiella pneumoniae from the urine. Antimicrob Agents Chemother 2011, 55:5893-5899.

70. Alexander BT, Marschall J, Tibbetts RJ, Neuner EA, Dunne MW, Ritchie DJ: Treatment and clinical outcomes of urinary tract infections caused by KPC-producing Enterobacteriaceae in a retrospective cohort. Clin Ther 2012, 34(6):1314-1323.

71. Qureshi ZA, Paterson DL, Potoski BA, Kilayko MC, Sandovsky G, Sordillo E, Polsky B, Adams-Haduch JM, Doi Y: Treatment outcome of bacteremia due to KPCproducing Klebsiella pneumoniae: Superiority of combination antimicrobial regimens. Antimicrob Agents Chemother 2012, 56(4):2108-2113.

72. Tumbarello M, Viale P, Viscoli C, Trecarichi EM, Tumietto F, Marchese A, Spanu T, Ambretti S, Ginocchio F, Cristini F, Losito AR, Tedeschi S, Cauda R, Bassetti M: Predictors of mortality in bloodstream infections caused by Klebsiella pneumoniae carbapenemase-producing K. pneumoniae: Importance of combination therapy. Clin Infect Dis 2012, 55(7):943-950.

73. Hirsch EB, Tam VH: Detection and treatment options for Klebsiella pneumoniae carbapenemases (KPCs): An emerging cause of multidrugresistant infection. J Antimicrob Chemother 2010, 65(6):1119-1125.

doi:10.1186/1476-0711-11-32

Cite this article as: Lee and Burgess: Treatment of Klebsiella Pneumoniae Carbapenemase (KPC) infections: a review of published case series and case reports. Annals of Clinical Microbiology and Antimicrobials ::

\section{Submit your next manuscript to BioMed Central and take full advantage of:}

- Convenient online submission

- Thorough peer review

- No space constraints or color figure charges

- Immediate publication on acceptance

- Inclusion in PubMed, CAS, Scopus and Google Scholar

- Research which is freely available for redistribution

Submit your manuscript at www.biomedcentral.com/submit
Biomed Central 